\title{
EL ANÁLISIS GEOMORFOLÓGICO EN LA RECONSTRUCCIÓN PALEOAMBIENTAL. ELEJEMPLO DE LOS PROCESOS DE ORIGEN FRÍO EN EL NOROESTE DE LA PENÍNSULA IBÉRICA
}

\author{
Augusto PÉREZ ALBERTI \\ Universidade de Santiago
}

RESUMEN: En el presente artículo se analiza el papel de la Geomorfología en la reconstrucción paleoambiental. Se considera que el análisis combinado de formas del relieve y depósitos sedimentarios permite, por un lado, comprobar la importancia de los cambios climáticos a lo largo del tiempo y, por otro, conocer su impronta morfogenética sobre los diferentes medios, ejemplarizada en el caso concreto de los procesos fríos que se sucedieron en el Noroeste de la Península Ibérica durante el Pleistoceno reciente.

La combinación del análisis morfológico con el sedimentológico ha permitido conocer el papel de los ambientes frío que dominaron, por lo menos, entre los 40.000 y los 11.000 BP. Las diferentes secuencias deposicionales existentes, tanto en la costa como en el interior, muestran no sólo la magnitud de los propios procesos sino también las características de la atmósfera a nivel general, de manera especial, la cantidad de humedad en el aire. Ello permite definir, por lo menos, una primera etapa fría, situada en torno a los 30.000 BP con manifestaciones periglaciares que se pueden denominar como húmedas, lo que singulariza al Noroeste respecto a otros lugares de la fachada atlántica europea, y, posteriormente, otras dos, más secas y frías, en torno al 18.000 B.P. y al 11.000 BP.

PALABRAS CLAVE: Península Ibérica, glaciar, periglaciar, paleoambiente.

ABSTRACT: The paper deals with the role of geomorphology as a palaeoenvironmental tool. We consider that studying both the shapes of landforms and deposits helps to determine the importance of weather changes that happen in the past and the morphogenetic indicators, particularly those active in the cold periods which occurred in the NW Iberian Peninsula during Late Pleistocene.

The study of morphology and deposits has permitted to precise the periods during which cold environments occurred, at least between 40 and $11 \mathrm{ka} \mathrm{B.P.} \mathrm{The} \mathrm{sedimentary} \mathrm{sequences} \mathrm{observed}$ along the coast and inland indicate not only the magnitude of the processes but also the general climatic conditions, particularly air moisture. The data collected has permitted to recognized the occurrence of a cold stage circa 30 ka B.P. Periglacial indicators suggest a humid environment for the NW Iberian Peninsula which differs from other areas of the European Atlantic coastal regions, and also two other drier and colder periods circa 18 and 11 ka B.P.

KEY WORDS: Iberian Peninsula, glacial, periglacial, palaeoenvironment.

RÉSUMÉ: Le présent article analyse le rôle de la Géomorphologie dans la reconstruction paléoenvironnementale. On considère que l'étude combinée des formes du relief et de dépôts sédimentaires permet de vérifier l'importance des changements climatiques au fil du temps d'une part, et de connaître leur empreinte morphogénétique sur les différents milieux d'autre part, prenant comme cas concret des périodes froides qui se sont succédées dans le nord-ouest de la Péninsule Ibérique pendant le Pléistocène récent.

La combinaison des études morphologiques et sédimentologiques a permis de connaître le rôle des milieux froids qui ont dominé au moins entre 40000 et 11000 BP. Les différentes séries sédimentaires existantes, aussi bien dans la côte qu'à l'intérieur, montrent non seulement 
l'ampleur des propres processus mais également les caractéristiques générales de l'atmosphère, notamment le pourcentage d'humidité dans l'air. Cela permet de définir au moins une première période froide, située autour de $30000 \mathrm{BP}$, avec des manifestations périglaciaires qui pourraient être qualifiées d'humides, ce qui distingue le Nord-ouest des autres endroits de la façade atlantique. Dans un deuxième temps on différencie deux autres périodes, plus sèches et plus froides, aux environs de $18000 \mathrm{BP}$ et $11000 \mathrm{BP}$ respectivement.

MOTS-CLÉS: Péninsule Ibérique, glaciaire, périglaciaire, paléoenvironnement.

RESUMO: Analisa-se no presente artigo o papel da Geomorfologia na reconstrução paleoambiental. Considera-se que o analise combinado de formas de relevo e depósitos sedimentários permite, por um lado, comprovar a importância dos câmbios climáticos ao logo do tempo e, por outro, conhecer sua marca morfogenética sobre os diferentes meios, exemplificada no caso concreto dos processos frios que sucederam no Noroeste da Península Ibérica durante o Plistoceno recente

A combinação do análise morfológico com o sedimento lógico permitiu conhecer o papel dos ambientes frios que dominaram, pelo menos, entre os 40.000 e os 11.000 BP. As diferentes seqüências de deposição existentes, tanto na costa como no interior, mostram não só a magnitude dos próprios processos mas também as características da atmosfera a nível gera, de maneira especial, a quantidade de humidade no ar. Isso permite definir, pelo menos uma primeira etapa fria, situada por volta dos 30.000 B P. com manifestações peri-glaciais que podem se denominar como húmidas o que singulariza ao Noroeste respeito aos outros lugares da fachada atlântica européia, e, posteriormente, outras duas, mais secas e frias, por volta aos $18.000 \mathrm{BP}$. E aos $11.000 \mathrm{BP}$.

PALAVRAS CHAVE: Península Ibérica, glaciar, periglacial, paleoambiente.

\section{INTRODUCCIÓN.}

En la actualidad existe una honda preocupación por los cambios que se puedan producir en el clima de la Tierra. Tanto que se ha convertido en uno de los temas de mayor presencia en los medios de comunicación. Por lo menos en ciertos momentos; cuando arrecian los temporales o cuando se instala una ola de calor, por ejemplo. Posiblemente el alarmismo que domina en muchos de los comentarios se vería matizado si se tuviese una información más precisa de la historia de la Tierra. Porque, no cabe duda de que, para los que se dedican a los estudios paleoambientales, no es nada nuevo el tema. Se sabe, desde hace tiempo, que el clima es cambiante por naturaleza y que, a lo largo de la historia de nuestro planeta, se han sucedido numerosos episodios, fríos o cálidos, secos o húmedos.

La incidencia de los cambios climáticos que ocurrieron en el pasado afectó, sin duda, a un número mucho más reducido de personas que en la actualidad. Más aún, en el pasado los cambios climáticos afectaron a sociedades menos desarrolladas, que no habían urbanizado amplios espacios, ni construido carreteras o puertos; que no habían ocupado las riberas de los ríos ni de los mares -o lo habían hecho en mucha menor medida- $y$, de manera especial, que no dispo- 
nían de unos medios de comunicación que transmitieran la información al instante.

Parece lógico pensar que el problema estriba, fundamentalmente, en el hecho de que un cambio en el clima va a traer consigo la necesidad de introducir modificaciones de todo tipo en las sociedades humanas. Sin embargo mucho nos tememos que ni las conferencias sobre el Cambio Climático, ni las investigaciones científicas podrán frenar una dinámica natural que se muestra cambiante. Otra cosa es frenar el Cambio Ambiental, fenómeno más amplio, no centrado en el clima únicamente en donde éste es una parte importante; minimizar el impacto de las actividades humanas; frenar las emisiones de gases de efecto invernadero, vertidos al mar y a los ríos, evitar la contaminación de los freáticos, la erosión de suelos o la deforestación, que sin duda introducen elementos enormemente nocivos para la salud de los seres vivos y, consecuentemente, para el clima. Sin embargo, no se trata de entrar a analizar estas cuestiones y, por ello, únicamente se enumeran. Se quiere dejar constancia solamente de un hecho: el clima es cambiante per se y conocer los climas del pasado va a permitir entender los climas que puedan existir en el futuro. Conocer el pasado es entender el presente y, consecuentemente, no saber que va a ocurrir en el futuro -siempre impredecible- sino planificarlo en función de las posibles modificaciones climáticas. Por ello, en una sociedad enamorada de la tecnología, los geomorfólogos junto con otros especialistas, pueden colaborar en la reconstrucción sin que, frente a investigaciones en otros campos de la ciencia, ello suponga grandes desembolsos económicos.

\section{ANÁLISIS GEOMORFOLÓGICO Y PALEOAMBIENTE.}

Es sabido que la Geomorfología tiene como objetivo primario la descripción de las formas del terreno y su evolución. Su análisis se centra de una manera clara en dos elementos básicos: las formas del relieve y los depósitos o, si se quiere, las formaciones superficiales.

\subsection{El estudio de las formas.}

El relieve -el aspecto visible de la litosfera- el conjunto de formas que sobresalen en cualquier lugar, se plasma en la combinación de planos con diferente inclinación. No hace falta decir que una llanura es un plano horizontal ni que una ladera es un plano que presenta una inclinación determinada. Sin embargo, sí que tiene importancia resaltar que la forma no es la única variable a tener en cuenta y que es fundamental tener presente la pendiente que ofrece cualquier forma/plano. Importancia por cuanto, en función de aquélla, asociada a la gravedad, funciona -o funcionó- de una manera concreta cualquier tipo de proceso. 
Es importante por cuanto la geometría de la forma está aportando datos en la reconstrucción.

Así, en un ambiente frío, si la pendiente supera los $25^{\circ}$, el grado de diaclasado de la roca en la parte superior de un farallón favorece la caída de derrubios por gravedad. No son necesarias condiciones de temperatura extremas para que se genere un talud de derrubios al pie de la pared. Incluso, en ciertos tipos de rocas, no son siquiera necesarias condiciones frías para que la acumulación se produzca. Por contra, si encontramos una ladera con una pendiente escasa, menor de $10^{\circ}-15^{\circ}$, cubierta de bloques, (slope blocks) es evidente que no pudo evolucionar únicamente por procesos vinculados a la simple gravedad. Si, además, la ladera presenta una cobertera completa, desde la parte superior a la parte inferior, únicamente se pudo haber acumulado en unas condiciones climáticas frías (FIGURA 1).

La forma, pues, condiciona el proceso y, al mismo tiempo, es el resultado de su sucesión a lo largo del tiempo. En la naturaleza la combinación de formas es una constante y podemos diferenciarlas tanto por su magnitud como por su aspecto o por su origen aunque hay que tener presente que en su mayoría son poligénicas, resultado de la interacción de diferentes procesos a lo largo del tiempo. Así, por su tamaño, podemos hablar de megaformas, mesoformas o microformas; por su aspecto, de erosión o de acumulación; por su origen de glaciares, periglaciares, fluviales, marinas, eólicas... Tenemos, pues, que cualquier forma tiene una triple lectura en función de su tamaño, de su aspecto y de su génesis. Supongamos una megaforma concreta: un valle glaciar. Puede presentar una forma en U cerrada, en cuna o en V. En su interior pueden aparecer mesoformas, como circos, umbrales rocosos, hombreras, lagos de sobre-excavación; microformas, como rocas pulidas, aborregadas, estriadas, cazoletas... o formas de acumulación, como morrenas laterales, fronto-laterales, centrales...

Tenemos, pues, que las formas de origen glaciar son de vital importancia a la hora de comprobar la impronta de los procesos de origen frío en un territorio. En el Noroeste de la Península Ibérica se puede encontrar una amplia gama de ellas. Así por ejemplo, si bien es cierto que los valles son elementos claves en los paisajes modelados por el hielo, no lo es menos que no siempre ofrecen un origen claro. La presencia de valles con formas en artesa o cuna no es sinónimo de glaciarismo. Sin embargo, cuando a la forma del valle se le asocian otros elementos morfológicos, como hombreras, umbrales, áreas de sobre-excavación glaciar, rocas pulidas o estriadas etc., se pueden catalogar sin ningún tipo de dudas. Ahora bien, en ocasiones, un perfil transversal en uve tampoco es sinónimo de la no existencia glaciarismo dado que en diferentes lugares se ven rupturas bruscas en perfil, tanto transversal como longitudinalmente al valle y, hay 
evidencias sedimentológicas de que han estado afectados por la dinámica glaciar.

Son relativamente numerosos los valles en los que, pese a no presentar una forma típica, el estudio de las facies sedimentarias, visibles en las formaciones superficiales existentes, demuestran con claridad la acción del hielo en el pasado; es el caso del tramo gallego del valle de Suárbol-Moreira, en Ancares, en donde aparecen materiales subglaciares, de acreción e de fusión en varios lugares así como restos de una morrena fronto-lateral que permiten conocer el paso del hielo (VALCÁRCEL DíAZ, 1998). Otro tanto sucede en los valles de Balouta, Ortigal, A Vara o Brego. En la Serra do Courel son muy frecuentes los valles en uve. Por contra, son escasos en el sector norte del Macizo de Manzaneda, mientras que podemos observarlos en el sur, dentro de los Montes do Invernadeiro, en los valles del río Conso o en la Ribeira Grande y Ribeira Pequena, así como en la Serra de San Mamede. El número de valles de origen glaciar es abundante en las montañas galaicas y en su entorno, por lo que las posibilidades de hacer una reconstrucción paleoambiental de los momentos fríos también lo es.

Asociados a muchos valles glaciares aparecen circos de tamaño variable, oscilando entre los 300-500 m de ancho en la Serra do Rañadoiro a los 1500 en algunos valles septentrionales del macizo de Trevinca. Buenos ejemplos se encuentran, en la Serra dos Ancares, Courel, Serra do Oribio y Manzaneda (PÉREZ AlBerTI, A. 1991; VALCÁRCEL DíAZ, 1998). Por lo general, los mejores ejemplos están orientados hacia el norte. En su interior es frecuente encontrar importantes acumulaciones de depósitos periglaciares, de tipo talud de derrubios, morrenas de nevero o glaciares rocosos, formados con posterioridad a la desaparición de los hielos -otro dato de suma importancia (FIGURA 2). El contacto de los circos con los valles se realiza por medio de umbrales. Unos son el fruto de cambios litológicos; otros de la debilidad tectónica, cuando no del incremento de la competencia del hielo debido a la coalescencia de lenguas. Frecuentemente llevan asociadas formas menores de erosión, como rocas aborregadas, pulimentos y estrías.

En algunos de los sistemas glaciares, el flujo de las lenguas de hielo por los valles principales erosionó con intensidad las paredes laterales del lecho por el que circulaban, originando en ellas un hombreras glaciares, que pueden ser utilizadas como indicadoras de su presencia en el pasado. En ocasiones están acompañadas de formas de acumulación y depósitos sedimentarios glaciares, como morrenas laterales, tills de acreción y fusión, o glaciolacustres, originados como consecuencia de la obturación de valles subsidiarios por parte de la lengua principal. De la vitalidad de los glaciares también nos dan fe las áreas de sobreexcavación glaciar que se ven en muchas cabeceras y a lo largo de los valles, frecuentemente asociadas a zonas de intersección de fracturas, a la presen- 
cia de rocas menos resistentes y a la estratificación en contra del flujo de las lenguas.

Y fruto de la acción abrasiva de los hielos son las áreas pulidas que se encuentran en diversos lugares del noroeste de la Península Ibérica. Localmente se aprecia un arrasamiento generalizado. En algún caso, la disposición de los estratos favoreció por igual la erosión y el modelado. En otros, parecen ser razones de dinámica local de las masas de hielo las responsables, dado que se localizan en antiguas difluencias glaciares. La gama de formas, pues, es lo suficientemente amplia para que no quepa duda del papel de las lenguas de hielo durante amplias etapas de la historia geomorfológica del Noroeste peninsular

\subsection{El estudio de los depósitos}

Y si las formas son elementos de primer orden en la reconstrucción, otro tanto o más lo son las formaciones superficiales analizadas a nivel de afloramiento. Mientras que las formas dan fe de la existencia de un proceso así como de su importancia a nivel territorial y de las grandes etapas evolutivas, el análisis sedimentario permite profundizar en la génesis de los diferentes medios geodinámicos.

En cada afloramiento se pueden diferenciar con relativa frecuencia distintas facies sedimentarias. Cada una de ellas se puede definir como aquella porción del depósito que posee unas características granulométricas y estructuras sedimentarias concretas que lo hacen diferenciarse de las que tienen al lado, sea en sentido vertical u horizontal. Las facies, al relacionarse entre sí, generan una secuencia o sucesión sedimentaria y, en función de su estructuración en corte, una arquitectura. En la FIGURA 3 se observa una sucesión de facies propia de un medio glaciolacustre. De muro a techo podemos diferenciar distintas facies. En la base ritmitas que se acumularon en un lago de aguas someras (b). Por encima aparecen acumulaciones deltaica (delta tipo Gilbert) (a) fruto de la entrada rápida de aguas de fusión que penetraron en un lago proglaciar, más profundo, de manera que la llegada del agua, cargada con material de tamaño gravas y cantos, propició un avance progradante con una clara grano-clasificación.

En la FIGURA 4 se ven ritmitas glaciares en las que su principal característica es la alternancia de niveles más claros, ricos en arena, o más oscuros, en los que dominan las micas, y en medio, algún canto (dropstone). Es evidente que su emplazamiento se produjo en un medio acuático, en un lago proglaciar. La deposición de las varvas derivó de la diferente agitación de las aguas, mayor en el verano y escasa o nula en el invierno, lo que permitió la decantación de las micas. La presencia de dropstones es indicativa de la existencia de bloques de hie- 
lo provenientes del glaciar, transportando gravas o cantos que se depositaron al fundirse sin perturbar en demasía las varvas.

Cuando en el campo se estudia con atención un afloramiento, cualquier investigador, con un mínimo de formación en las técnicas de observación y análisis, puede observar una amplia riqueza de matices. El análisis de los materiales de origen glaciar muestra una gran variedad de facies así como una acusada diversidad granulométrica. Se pueden encontrar depósitos matriz-soportados que pasan vertical u horizontalmente a clasto-soportados lo que indican como en los frentes glaciares se producían movimientos en masa con predominio de cantos (debris flow) o de finos (mud flow), como aguas de fusión que dieron lugar a depósitos más lavados (melt water) (FIGURA 5). El control litológico se manifiesta, sin embargo, de manera clara. Así, en los tills de las áreas graníticas, dominan cantos y bloques que, en algunos casos, pueden alcanzar 3-4 metros en su eje mayor y, por el contrario, los cantos de menor tamaño son los dominantes en los tills de las áreas esquisto-pizarrosas.

En los depósitos fluvioglaciares, fruto de la fusión de las masas de hielo, que están presentes en los valles de los ríos Eume (Serra do Xistral); Suárbol, Piornedo, Ancares, Burbia, Porcarizas o A Fornela en los Ancares (VALCÁRCEL DíAZ, M., 1998); As Lamas-Prada y Cenza en Manzaneda (PÉREZ AlBERTI, A. 1991), o A Ponte, Seoane y Bibei (PÉREZ AlBERTI, A. et al, 2002) en el macizo de Trevinca, las estructuras sedimentarias permiten diferenciar secuencias deposicionales identificadas en función del grado de energía del agua de fusión. $\mathrm{Y}$, aunque de escasa extensión, los depósitos glaciolacustres son de un enorme valor para poder conocer las fluctuaciones del frente glaciar. Así, por ejemplo, en los depósitos acumulados en el valle del río Bibei, en Pías (Zamora), con una potencia vista que no supera los $4 \mathrm{~m}$, es posible diferenciar facies bien definidas. Por una parte aparecen ritmitas limo-arenosas que se acumularon en condiciones de turbidez y que, en su mayoría, presentan una laminación horizontal, con capas alternantes claras y oscuras que varían entre los $2 \mathrm{~mm}$ y $1 \mathrm{~cm}$ de espesor. Localmente se pueden ver ondas ("ripples”) y ondas remontantes (“climbing ripples") que indican con claridad cambios en la velocidad y espesor de la capa da agua, así como, fundamentalmente, en la cantidad de material en suspensión que transportaba cuando penetraba en el área lacustre.

Y si los depósitos de origen glaciar permiten conocer el medio sedimentario otro tanto sucede con las formas de acumulación que aparecen en la mayor parte de los valles, que son de gran ayuda para entender cómo funcionaron los sistemas glaciares; hasta dónde llegaron los hielos o cuál fue la capacidad de transporte de las lenguas. El hecho, por ejemplo, de que apenas se encuentren morrenas fronto-laterales correspondientes a la máxima expansión de los glaciares ya está aportando un dato de interés: la importancia del roquedo en las caracte- 
rización de los elementos constitutivos de las morrenas y, consecuentemente, en su conservación. Únicamente en algún valle es posible verlas; siempre asociadas a la presencia de rocas graníticas. Al respecto destacan los complejos morrénicos fronto-laterales de Piornedo, en los Ancares (FIGURA 6); los del valle de As Lamas-Prada, en Manzaneda; las de Lago de Sanabria, en Trevinca, como formas típicas que se emplazan -las más bajas- en torno a los $900 \mathrm{~m}$ de altitud. Otras morrenas presentan un aspecto lineal delimitando el contorno lateral de las antiguas líneas glaciares. Dentro de este tipo, destacan las laterales del margen derecho del valle del Bibei en el sector de Cepedelo (FIGURA 7).

Pero no sólo los depósitos de origen glaciar son básicos para la interpretación paleo-ambiental; los de origen periglaciar juegan un papel sin duda de mayor importancia dado que no sólo indican la presencia de procesos hielo/deshielo sino que, por la tipología de sus facies y estructuras sedimentarias, aportan datos del máximo interés. También se ha identificado una amplia gama de formas de acumulación de origen periglaciar (PÉREZ ALBERTI, 1979, 1983, 1991; PÉrez Alberti et al. 1993; PÉrez Alberti, A. y VAlCÁrCel DíAz, M., 2000) semejantes a otras muchas descritas en la literatura científica en diferentes lugares afectados por el frío en etapas anteriores o que son activos en la actualidad. Los depósitos se pueden identificar, en algunos casos, por sus características a nivel de afloramiento, como sucede con los grèzes litèes, las arènes litèes o los derrubios estratificados, o por dibujar una forma concreta, como sucede con los glaciares rocosos o las morrenas de nevero. En estos casos son unos magníficos indicadores paleoambientales dado que reflejan unas condiciones de deposición precisas. En otros, los depósitos o las formas de acumulación que se asocian a ellos tienen un valor morfo-sedimentario más que paleoclimático, pudiendo tener su origen en condiciones ambientales poco precisas, aunque si se presentan fosilizando o siendo fosilizados por otros depósitos pueden indicar variaciones en las condiciones paleo-ambientales.

Tanto en el interior como en la costa del territorio analizado, se encuentran depósitos de origen periglaciar de muy diferente tipo, como ya se ha señalado con anterioridad. Sin embargo, los depósitos del litoral contienen en su interior diferentes paleosuelos que son de vital importancia a la hora de reconstruir. Porque, no cabe duda, que si enlazamos formas y depósitos significativos con suelos o paleosuelos es posible no sólo reconstruir el medio sedimentario que permita llevar a cabo una reconstrucción, sino enmarcar los procesos en el tiempo (FIGURA 8).

Prácticamente, en todo el litoral que se alarga desde el río Eo al Miño aparecen acumulaciones sedimentarias. Se puede afirmar que el frente costero está en un alto porcentaje fosilizado por depósitos de origen continental. Como ya se ha dicho anteriormente (PÉREZ ALBERTI et al., 1998), los depósitos mejor conser- 
vados se encuentran en las zonas protegidas y están en la actualidad sometidos a fuertes procesos erosivos lo que dificulta conocer con exactitud cual ha sido su extensión inicial. Sus rasgos morfo-sedimentarios muestran el papel de los factores locales en la deposición. En algunos lugares rellenan antiguas ensenadas, bordeadas por acantilados bajos; en otros, los acantilados adquieren un mayor desarrollo lo que trajo consigo la presencia de pendientes más abruptas y laderas de mayor longitud con lo que las formaciones superficiales cubren su parte basal; en unos terceros, tras acantilados relativamente bajos, se extienden diferentes sierras litorales, desde la que surgen valles, con diferente grado de encajamiento, o laderas empinadas, que se convierten en canalizadores de diferentes flujos de derrubios (FIGURA 9).

La diferenciación morfológica trajo consigo importantes modificaciones en la caracterización de las distintas formaciones sedimentarias. Lo anterior muestra que, a medida que aumenta la altitud y la proximidad de las laderas a la línea de costa, el ambiente climático claramente periglaciar en los sectores de menor altitud, pasa a estar marcado por lo nival o, incluso, por lo glaciar. Esto explica como, en un ambiente general frío, las condiciones topográficas locales introdujeran factores diferenciadores.

\section{LA SÍNTESIS.}

Los estudios paleoclimáticos llevados a cabo en el Noroeste de la Península Ibérica (TRICART \& PÉREZ ALBERTI, 1989; PÉREZ AlBERTI, 1991; VALCÁRCEL DÍAZ \& PÉREZ ALBERTI, 1996; VALCÁRCEL DÍAZ, 1998) permiten conocer bastante bien cual ha sido su evolución paleoambiental. El análisis de las formas y depósitos en la Sierra de Ancares (VALCÁRCEL DíAZ, 1998) ha permitido conocer la existencia de tres fases geocriológicas mayores: una de máximo avance, otra fase intermedia y por último, una tercera en la que los glaciares se cobijaron en las partes más elevadas de la sierra, por encima de los $1500 \mathrm{~m}$ de altitud. Una evolución parecida se puede observar en otros macizos, caso de Manzaneda (PÉREZ AlBERTI, 1991). Al mismo tiempo, al analizar las formas, depósitos $y$, lo que es importante, las estructuras, de origen periglaciar, se observa un claro escalonamiento, en este caso en Ancares, la sierra más profundamente estudiada (PÉREZ ALBERTI, 1983, 1986, 1991; VALCÁRCEL DÍAZ, 1998) con claras evidencias de haberse generado suelos helados. Se puede ver una dinámica periglaciar, relacionada con la presencia de condiciones ambientales propicias para la génesis de procesos de hielo/deshielo con ritmos diversos, sujetos, al igual que otros fenómenos naturales a leyes de zonación geográfica. Así, una taxonomía geocriológica establece en su nivel superior tres grandes pisos o cinturones: un piso de permafrost, caracterizado por la presencia permanente de hielo; un piso de congelación, en el que los fenómenos de congelación se producen sólo en un período del año, con la formación, en todo caso de suelos helados, 
gelisoles, y por último un piso con presencia de alternancias de hielo/deshielo en ciclos cortos (GORBUNOV, 1978). Las consecuencias de la presencia de uno u otro piso en un área determinada serán diferentes en cada caso. Por ejemplo, la presencia de permafrost originará formas características tales como glaciares rocosos o ciertos campos de bloques. Por contra, la presencia de un hielo estacional profundo dará lugar a otro tipo de formas, como es el caso de las crioturbaciones. Por otra parte, la superposición en un mismo sector de facies morfosedimentarias distintas nos habla con claridad de una sucesión en el tiempo de condiciones paleoambientales diferentes.

Es evidente que, al igual que otros pisos controlados en último término por las condiciones macroclimáticas generales, estos ascendieron o descendieron en altitud en la medida que unas condiciones climáticas, referidas en el tiempo, paleoclimáticas, variaron. Así, un descenso de la temperatura media debe ir acompañado de un descenso relativo del límite inferior de estos pisos. Sin embargo, al igual que ocurre con el fenómeno glaciar, la temperatura no es el único factor climático que controla la dinámica periglaciar. La humedad es otro elemento fundamental a tener en cuenta.

En las áreas de montaña aparecen formas características de este tipo de fenómenos, tales como glaciares rocosos fósiles, campos de bloques, cuñas de hielo fósiles o suelos crioturbados. Son todos indicios de la presencia de suelos helados de uno u otro tipo, y tienen un gran valor a la hora de realizar una reconstrucción paleoambiental, dado que estas formas aparecen solamente cuando se dan unas condiciones de temperatura y precipitación precisas. Por ello, pueden ser utilizadas como indicadores, y consecuentemente, como indicadores paleoambientales (KERSCHNER, H. 1978; HUMLUM, 1982; HAEBERLI. 1983).

Si se centra el análisis en el caso de los glaciares rocosos, se comprueba que actualmente todos los que se hallan activos en el planeta se encuentran en aquellos lugares donde las temperaturas medias anuales del aire (TMAA) son, por lo menos, inferiores a los $-2^{\circ} \mathrm{C}$ (HAEBERLI, 1983; HuMLUM, 1982). Esta isoterma marca también el límite inferior del llamado permafrost discontinuo, plasmado en suelos helados permanentemente únicamente en exposiciones norte o noreste, por lo que los glaciares rocosos están indicando el límite inferior del permafrost. Nada impide pensar que si ello ocurre en la actualidad debió funcionar de manera semejante en el pasado y dado que este tipo de formas fósiles aparecen en la Serra dos Ancares (FIgURA 10) o en diferentes lugares próximos de la Cordillera Cantábrica, no es difícil suponer que, cuando se originaron, existía un cinturón de suelos helados en estos sectores del noroeste peninsular. Otro tanto sucede con ciertos campos de bloques de origen periglaciar, extensiones horizontales de macroclastos que requieren para su formación la presencia de permafrost continuo, o sea, temperaturas inferiores a los $-6^{\circ} \mathrm{C}$ de TMAA. Los 
campos de bloques aparecen en las superficies aplanadas que dominan las cumbres de la mayor parte de las sierras gallegas, tales como Ancares, Queixa y Trevinca, por lo que también son una buena herramienta a la hora de establecer reconstrucciones paleoclimáticas (FIGURA 11).

Además de estas formas originales, existen otros elementos que se pueden emplear, tales como la presencia de cuñas de hielo fósiles, como las descritas en el valle del río Moia, afluente del Río Navia, (PÉREZ AlberTI, A. y VALCÁRCEL DíAZ, M., 1996) (FIGURA 12), que denotan la presencia de suelos helados a cotas relativamente bajas, como son los 500-600 m, o las crioturbaciones y la presencia de horizontes endurecidos (fragipán) en los suelos, que en todo caso señalan la presencia de suelos helados estacionalmente en profundidad, cuando no un auténtico permafrost (PÉREZ ALBERTI, 1991; VALCÁRCEL DÍAZ \& PÉREZ AlBERTI, 1996; VALCÁRCEL DÍAZ, 1998).

Y si, a partir del análisis de las formas y depósitos periglaciares es posible conocer las características paleoclimáticas reinantes, otro tanto se puede lograr si se pone en relación el fenómeno periglaciar con el glaciar. Se sabe que la formación de glaciares responde a un equilibrio dinámico frío/humedad. Según esto se pueden diferenciar dos modelos extremos de glaciarismo. Uno, condicionado por el gran aporte de humedad en forma de nieve dentro de un contexto frío, pero que no requeriría temperaturas medias anuales extremadamente bajas lo que propiciaría la génesis de un glaciarismo de tipo oceánico controlado principalmente por la abundancia de precipitaciones en forma sólida. Otro, contrapuesto, estaría apoyado en la existencia de un frío extremo, y originaría un glaciarismo continentalizado frío/seco. Estos dos modelos y todas sus variedades de transición, se dan en la actualidad en nuestro planeta. Los estudios sobre la evolución geomorfológica llevados a cabo en el noroeste de la Península Ibérica, demuestran a lo largo del Pleistoceno superior se dieron condiciones que variaron entre los dos modelos citados.

Todo glaciar se puede dividir en dos sectores según la dinámica de acumulación/ablación: una parte superior o área de acumulación, y otra inferior o área de ablación, separadas por una línea llamada Línea de Equilibrio Glaciar (ELA según sus iniciales en inglés). La temperatura de la ELA puede variar según el tipo de glaciarismo entre valores, deducidos a partir del estudio de glaciares activos, que oscilan entre los $0^{\circ} \mathrm{C}$ hasta los $-14^{\circ} \mathrm{C}$ (FRANCOU, 1989). Es evidente que en el glaciarismo oceánico la ELA estaría por debajo del límite de cualquier suelo helado y que por debajo de la ELA, en el glaciarismo continentalizado, se desarrollarían todo tipo de suelos helados. Si se puede establecer una relación entre los glaciares y la presencia de suelos helados será posible proponer un modelo geocriológico que defina el tipo de clima frío que se da en un momento determinado. Los estudios sobre climas fríos pleistocenos en Galicia, especial- 
mente los desarrollados con gran rigor por M. Valcárcel Díaz en su tesis doctoral (1998) permiten establecer una sucesión de fases geocriológicas diferenciadas a lo largo de, por lo menos, el Pleistoceno Final, que ponen en relación la dinámica glaciar y la dinámica periglaciar.

El citado autor ha establecido un primer momento caracterizado por la presencia en Galicia de una fase geocriológica oceánica, condicionada por el gran aporte de nieve dentro de un contexto frío aunque no extremo, dado que no se detecta la presencia de suelos helados por debajo del nivel de la ELA en los distintos macizos montañosos. Se correspondería con el momento de máximo avance de los glaciares en las montañas gallegas. El descenso de las temperaturas medias anuales con respecto a las medias actuales necesario para que se diese esta fase sería del orden de $6^{\circ} \mathrm{C}$.

Con posterioridad se ha desarrollado un segundo momento frío correspondiente a una fase geocriológica continentalizada, en la que, junto a la presencia de glaciares en las montañas más elevadas se ha detectado la aparición de suelos helados por debajo del nivel de la ELA. Este momento sería más frío que el anterior, dándose un descenso de unos $12^{\circ} \mathrm{C}$ de descenso de las temperaturas medias anuales, aunque los glaciares serían menos extensos que en la fase anterior debido a una disminución en el aporte de humedad ya que, en respuesta al descenso de las temperaturas, el clima global se hace más seco. Únicamente se conocen para esta fase los valores teóricos de las temperaturas medias, así como el hecho de la existencia de una restricción importante en el ciclo hidrológico. Se daría una amplitud térmica muy grande, con los meses de invierno muy fríos y con olas de frío que harían bajar las temperaturas por debajo de los $-25^{\circ} \mathrm{C}$. En estas condiciones el suelo permanecería helado. Sin embargo, en un corto verano las temperaturas se situarían por encima de los $0^{\circ} \mathrm{C}$ y se daría un deshielo, por lo menos superficial. Se trataría de un clima del tipo que en la actualidad se da en la tundra siberiana.

Finalmente, el estudio del glaciarismo y de los suelos helados, ha permitido distinguir una última fase geocriológica continentalizada de altitud, que se puede desdoblar en dos momentos. En todo caso sería menos fría y estaría marcada por la presencia de glaciares rocosos emplazados en los sectores más elevados de las sierras orientales de Galicia (Ancares, Degaña, ...) coetáneos o posteriores al retroceso final de los glaciares. El descenso de la temperatura media sería del orden de los $6-7^{\circ} \mathrm{C}$, similar a la fase geocriológica oceánica, lo que indica que la disponibilidad de humedad en este momento sería mucho menor.

Los datos aportados por las formas y depósitos encontrados en el interior se ven complementados por aquellos que, a modo de manto casi continua, cubren el litoral nor-occidental. Dada la dificultad de abordar el estudio de todos ellos 
se han seleccionado aquellos más significativos. Uno de ellos se encuentra en Caamaño, lugar emplazado en el margen sur de la ría de Muros y Noia, sobre una antigua plataforma litoral. En su base se localiza una playa cementada (COSTA CASAIS, 1996, COSTA CASAIS, 2000, TRENHAILE et al., 1999) posiblemente del último interglaciar, cuando el nivel del mar alcanzó cotas similares a las actuales o un poco más altas (SHAKLETON y OPDYKE, 1973). Un nivel de playa semejante es posible verla en el sector de Arnela (Muxía) (PÉREZ ALBERTI et al., 1999) (FIGURA 13), fosilizada por depósitos de origen periglaciar igual que el área de Nois (Foz); en Baldaio o Traba, en la Costa da Morte; en el área de Ferrol; en la Ría de Muros e Noia o en el sector que se alarga entre Cabo Silleiro y A Guarda, entre otros.

En numerosos lugares se pueden ver afloramientos en los que las facies más características y de mayor potencia son de origen continental, fruto de una dinámica de "continentalización" progresiva asociada a una bajada eustática del nivel del mar (VAN VLIET-LANÖE, 1986, 1989). Los diferentes niveles orgánicos que aparecen en los distintos afloramientos se formarían en momentos fríos, pero con relativa humedad ambiental, y denotan momentos de estabilidad en el paisaje. Dataciones radiocarbónicas en depósitos localizados al sur de Galicia, en San Xián y Oia (CANO, et al., 1997); en Caamaño (COSTA CASAIS, 1996) o Arnela (PÉREZ ALBERTI et al.1999), permiten establecer dos momentos de formación de suelo en el Pleniglaciar Medio. Uno entre los 40.000 y los 30.000 BP

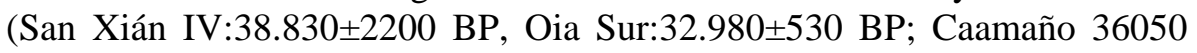
+1430 -1210 BP y $32340+2400-1800$ BP o Arnela, $37.550 \pm 690,34.700 \pm$ 450, $35.620 \pm 1.150,34.530 \pm 470,34.380 \pm 670,31.740 \pm 360,31.050 \pm 340$ BP) y otro entre el $30.000 y$ el 20.000 BP (San Xian I en $28.000 \pm 230$ BP; Camaño: $30120+670-620$ BP y $20160 \pm 270$ BP).

Un primer momento se habría desarrollado entre el 32.000 y el 30.000 BP; un segundo con posterioridad al 20.000 BP, posiblemente en torno al 18.000 BP, momento de máximo frío y sequedad ambiental, y por tanto, de máxima continentalidad. En este momento serían muy frecuente las acumulaciones de tipo head (VAN VLIET-LANÖE, 1986,1989). En la a primera fase fría, dominaría un ambiente más húmedo, lo que provocaría la existencia de un glaciarismo generalizado en toda Galicia y un periglaciarismo reducido a ciertas zonas de mayor altitud. En la costa la humedad favorecería los movimientos en masa solifluidales. Es lo que podríamos denominar "periglaciar húmedo", no citado en otros lugares de Europa. En la segunda fase, el ambiente más frío y seco favorecería el ascenso de la ELA en el interior de Galicia y la puesta en marcha de procesos periglaciares, nivales o glaciares -según los sectores- en la costa dominando procesos variados desde la crioreptación o gelifluxión hasta la fusión nival. 


\section{CONCLUSIONES.}

La reconstrucción paleoambiental requiere un análisis integrado. La Geomorfología aporta una herramienta de enorme utilidad. Para ello es necesario seguir una serie de pasos (FIGURA 14). En primer lugar, llevar a cabo una detallada cartografía geomorfológica. La localización precisa de las diferentes formas y depósitos facilitará una mejor comprensión de las variadas problemáticas. El análisis sedimentológico, a nivel de afloramiento, introduce un valor añadido al proporcionar no solo información en lo referente al medio sedimentario sino que, cuando aparecen perturbaciones sin o post-deposicionales, caso de crioturbaciones, introduce una información de enorme valor paleoambiental.

La combinación de la descripción de las formas con el análisis sedimentológico ha permitido conocer las diferentes fases frías que se han sucedido en el Noroeste de la Península Ibérica. La comparación de medios sedimentarios antiguos con otros activos, especialmente de Canadá, Islandia o Argentina, han permitido realizar una precisa identificación de procesos y, consecuentemente, de paleoclimas. Las dataciones realizadas en la costa y en el interior de Galicia han permitido situar en el tiempo alguno de los procesos, desarrollados durante el Pleistoceno reciente. Sin embargo, hay que resaltar que el estudio evolutivo en el espacio debe ser una tarea primordial que, si se dispone de medios fiables, puede venir acompañada por su ubicación temporal. Ahora bien, la no existencia de dataciones, no empaña en absoluto la interpretación; únicamente deja en suspense una parte de la reconstrucción que podrá ser cubierta en el futuro. Por otra parte, las actuales controversias sobre las dataciones, no hacen más que introducir elementos de duda que, en ningún caso, pueden hacer creer a los investigadores lo baldío de su esfuerzo.

\section{BIBLIOGRAFÍA.}

BENEDICT, (1979): «Downslope soil movement in a Colorado aline region: rates, processes, and climatic significance». Artic Alp. Res., 2, pp. 165-226.

BLANCO CHAO, R. (1999): Formas y procesos geomorfologicos diferenciados en las costas de Galicia. Tesis Doctoral. Univesridade de Santiago. Inédita.

Blanco Chao, R.; Costa Casais, M.; Martínez Cortizas, A.; PÉRez ALBERTI, A.; TRENHAILE, A.S. (2003): «Evolution and inheritance of a rock coast: western Galicia, Northwestern Spain». Earth Surface Processes and Landforms, $\mathrm{n}^{\circ}$ 28, vol. 7, 757-775. Londres.

CAMPY, M. \& MACAIRE, J.J. (1988): Géologie des formations superficielles. Géodinamique-facies-utilisatión. Ed. Masson, 443 pp. París.

CANO, J.; FUMANAL, M-P.; FERRER, C.; USERA, J.; BLÁZQUEZ, A.M. OLMO, J. (1997): «Evolución de la costa meridional de Galicia durante el Cuaternario superior». Cuaternario Ibérico, P.33-46. 
Costa Casais, M.; Martínez Cortizas, A. \& Pérez Alberti, A. (1994): «Caracterización de un depósito costero de la ría de Muros-Noia (La Coruña, Galicia)». En ARNAEZ, GARCíA RUIZ y GOMEZ VILlAR (Eds.): Geomorfología en España. Sociedad Española de Geomorfología, pp. 356-368. Logroño.

Costa Casais, M., Martínez Cortizas, A. y Pérez Alberti, A. (1996): «Tipos de depósitos sedimentarios entre Fisterra e Corrubedo (A Coruña)». En: Pérez Alberti, A., Martini, I.P., Chesworth, W., Martínez CoRTIZAs, A. : Dinámica y evolución de medios cuaternarios.417-430. Xunta de Galicia. Santiago.

COSTA CASAIS, M. (1996): Formas e procesos costeiros nun sector da costa occidental galega (dende Fisterra ata Corrubedo). (Depósitos costeiros e evolución xeomorfolóxica). Memoria de Licenciatura. Universidade de Santiago. Inédita.

Costa CASAIS, M. (2001): Dinámica xeomorfolóxica e reconstrucción paleoambiental dun sector da costa occidental atlántica de Galicia (FisterraCorrubedo). Universidade de Santiago.

CHAPELL, J. y SHAKLETON, N.J. (1986): «Oxygen isotopes and sea level». Nature. vol.324; 137-140.

DYLIK, J. (1967): «Solifluxion, congelifluxion and related slope processes». Geografiska Annaler, 49, ser. A, 2-4. pp. 167-177

EYLES, N., EYLES, C. H. \& MiALL A.D. (1983): «Litofacies types and vertical profile models; an alternative approach to the description and environmental interpretation of glacial diamict and diamictite sequences». Sedimentology, 30. pp. 393-410.

FRANCOU, B. (1989): «La stratogénesè dans les formations de pente soumises à l'action du gel. Une nouvelle conception du problème». Bulletin de l'Association française por l'Etude du Quaternaire, 40, 185-1999.

FRANCOU, B. (1990): «Stratification mechanisms in slope deposits in high subequatorial mountains». Permafrost and Periglacial Processes. 1. pp. 249263.

FRANCOU, B \& HETU, B. (1989): «Eboulis et autres formations de pente heterometriques. Contribution a une términologie géomorphologique». Notes et Comptes-Rendus du groupe de travail "Regionalisation du Périglaciaire". Fasc. XIV. pp. 11-69.

GoRBunOV, A.P. (1978): «Permafrost investigations in high-mountain regions». Arctic and Alpine Research, 10, 2, 283-294.

GuILliEN, Y. (1951): «Les grèzes litées de Charente». Revue Géographique des Pyrénees et du Sud-Ouest, 22. pp. 153-162. 
HAEBERLI, W. (1983): «Permafrost-glacier relationships in the Swiss Alps, today and in the past». Proceedings of the IV International Conference of Permafrost. Fairbank, vol. I. 415-420.

HumLuM, O. (1982): «Rock glaciers in northern Spitsbergen: A discussion». Journal of Geology, 90, 214-221.

KERSCHNER, H. (1978): «Paleoclimatic interferences from Late Würm rock glaciers, Eastern Central Alps, Western Tyrol, Austria». Arctic and Alpine Research, 635-643.

KIRKBY, M. J. \& STATHAM, I. (1975): «Surface stone movement and scree formation». Journal of Geology. 83, pp.349-362.

MiALL, A.D. (1977): «A review of the braided river depositional environment». Earth Science Review, 13, pp 1-62.

MIALL, A.D. (1978): «Lithofacies and vertical profile models in braided rivers: a summary». En A.D. MiALL, (Ed). Fluvial Sedimentology. Canadian Society of Petroleum Geologists. Calgary, mem. 5. pp 597-604.

MiALL, A.D. (1992): «Alluvial deposits». En WALKER, R. G. and JAMES, N. P. (Eds.): Facies Models: Response to sea-level change. Geological Association of Canada. pp 119-142.

Moares Dominguez, C., Martinez Cortizas, A. \& Pérez Alberti, A. (1993): «Procesos de edafización sobre algunos materiales de origen periglaciar en las Sierras Orientales de Galicia (NW de la Península)». En: PÉREZ Alberti, A., Guitián RiVERA, L. \& RAMil REgo, P. (Eds.): La evolución del paisaje en las montañas del entorno de los Caminos Jacobeos. pp 61-90. Xunta de Galicia. Santiago

Ozouf, J-C.; COUTARD, J-P.; TEXIER, J-P. \& BERTRAn, P. (1993): Colloque "Processus et depots periglaciaires de versant". Excursión "Grèzes Litées". Comission "Les Milieux periglaciaires" (U.G.I.), Groupe de travail des Procesus et Environnements Periglaciaires (A.I.P.), Associaction Francaise du Pergelisol (A. F. P. ), Charentes- Perigord.

PÉREZ AlBERTI, A. (1979): «Nuevas observaciones sobre glaciarismo y periglaciarismo en el NW de la Península Ibérica. La Galicia sudoriental». Acta Geológica Hispana. Homenage Ll. Solé Sabarís. pp 441-444.

PÉREZ AlBERTI, A. (1983): «Procesos periglaciares e glaciares no Nordeste de Galicia». Revista Terra 3. Sociedade Galega de Xeografía. Entregado en 1983). Santiago (1988). pp 78-86.

PÉREZ AlBeRTI, A. (1991): La Geomorfología de la Galicia Sudoriental. Tesis doctoral. Universidade de Santiago.

PÉREZ AlberTi, A. \& Rodríguez Guitián, M. (1993): «Formas y depósitos de macroclastos y manifestaciones actuales de periglaciarismo en las Sierras Septentrionales y Nororientales de Galicia». En PÉREz Alberti, A., GUitián RiverA, L. \& RAMIL REgO, P. : La evolución del paisaje en las 
montañas del entorno de los caminos jacobeos. Xunta de Galicia, pp. 91106.

PÉREZ AlberTi, A., RodríGUez Guitián, M. y VALCÁRCEL DíAZ, M. (1993): «Las formas y depósitos glaciares en las Sierras Septentrionales y Orientales de Galicia». En PÉrez AlBerti, A., Guitián Rivera, L. y RAMIL RegO, P.: La evolución del paisaje en las montañas del entorno de los caminos jacobeos. Xunta de Galicia, pp. 61-90.

Pérez Alberti, A., Martínez Cortizas, A.y Moares Domínguez, C. (1994): «Los procesos periglaciares en el Noroeste de la Península Ibérica». En Gómez OrTiz, A., Simón TORREs, M. \& SALVADOR FranCH, F. (Eds.): Periglaciarismo en la Península Ibérica, Canarias y Baleares. Universidad de Granada. Granada, pp. 33-54.

Pérez Alberti, A. y Covelo Abeleiras, P. (1996): «Reconstrucción paleoambiental de la dinámica glaciar a partir de los depósitos acumulados en el sector de Pías (Valle del río Bibei, Zamora-Ourense)». En: PÉREZ ALBERTI, A., MARTINI, I.P., CHESWORTH, W., MARTínez CORTIZAS, A. : Dinámica y evolución de medios cuaternarios. 115-129. Xunta de Galicia. Santiago.

PÉRez Alberti, A.; Blanco ChaO, A. y Costa Casais, M. (1997): «La importancia de los balances de acumulación/erosión y fosilización/exhumación en la evolución geomorfológica de la costa de Galicia». En Dinámica de Litoral-Interior. Actas del XV Congreso de Geógrafos Españoles. Vol. 1. P.205-219.

PÉREZ AlBerTI, A. \& VALCÁRCEL DÍAZ, M. (1998): «Caracterización y distribución espacial del glaciarismo en el noroeste de la Península Ibérica». En A. GOMEZ OrTiz \& A. PÉREZ AlBerti (Eds.): Las Huellas Glaciares de las Montañas Españolas. Servicio de publicacions da Universidade de Santiago de Compostela. pp. 17-54.

PÉREZ AlBerTi, A., Blanco ChAO, R.; Costa CASAIS, M. (1998): «Depósitos sedimentarios antiguos en la costa atlántica gallega: tipología, localización y área fuente. Un análisis comparativo». En: A. GómEZ ORTIZ y F. SALVADOR FRANCH (eds.) Investigaciones Recientes de la Geomorfología Española, 341-346. Universitat de Barcelona. Barcelona.

Pérez Alberti, A., Costa Casais, M. \& Martínez Cortizas, A. (1999): «Nuevas aportaciones al conocimiento del Cuaternario reciente en la costa atlántica de Galicia». In Geoarqueología i Quaternary litoral. Memorial María Pilar Fuman, 381-390. Universitat de Valencia. Valencia.

PÉREZ AlBerTi, A. y VALCÁRCEL DíAZ, M. (2000): «Depósitos de ladera de estructura estratificada en la Galicia oriental (Noroeste Ibérico)». En: PEÑA, J.L., SÁNCHEZ, M. y LOZANO, M.V. : Los procesos y formas periglaciares en la Montaña Mediterránea. 25-44. Instituto de Estudios Turolense. Teruel. 
PÉRez ALBerTi, A., VALCÁRCEl DíAZ, M. y P. MARTini (2002): «La deglaciación en la vertiente suroccidental del Macizo de Peña Trevinca (Montañas de Trevinca, NW Ibérico)». En: Estudios recientes (2000-2002) en Geomorfología, Patrimonio, Montaña, Dinámica Territorial. SEG/Universidad de Valladolid. Valladolid.

SHACKLETON, N.J. y OPDYKE, N.D (1973): «Oxigen isotope and paleomagnetic stratigraphy of Equatorial Pacific core V28-238: oxygen isotope temperatures and ice volumes on a $10^{5}$ year scale». Quaternary Research, 3:39-55

Trenhaile, A. S., Pérez Alberti, A., Martínez Cortizas, A., Costa CASAIS, M. \& BLANCO CHAO, R. (1999): «Rock coast inheritance: an example from Galicia, Northwestern Spain». Earth Surface Processes and Landforms, $\mathrm{n}^{\circ} 24,1-17$.

TRICART, J. (1981): Geomorphologie climatique. En col: Précis de Geomorphologie. Tome III. ed. SEDES. Paris.

TRICART, J. \& PÉREZ AlBERTI, A. (1989): «Problemas de paleoclimatología: importancia e impacto del frío durante el Cuaternario». Actas do Simposio internacional "Otero Pedrayo e a Xeografía de Galicia", pp. 74-91. Consello da Cultura Galega. Santiago de Compostela.

VALCÁRCEL DÍAZ, M. (1998): Evolución geomorfológica y dinámica de las vertientes en el NE de Galicia. Importancia de los procesos de origen frío en un sector de las montañas lucenses. Tesis doctoral. Universidade de Santiago de Compostela. Inédita.

VAlCÁRCEl DÍAZ, M. y PÉREZ AlberTI, A. (1996): «Caracterización y cartografía de las formaciones superficiales de origen periglaciar en el valle de Moia (Cuenca del río Navia, NO Ibérico)». En: PÉREZ AlBERTI, A., MARTINI I.P., CHESWORTH, W., MARTínez CORTIZAS, A.: Dinámica y evolución de medios cuaternarios, 191-202. Xunta de Galicia. Santiago de Compostela. VALCÁRCEL DIAZ, M. \& PÉREZ ALBERTI, A (1996): «Caracterización y cartografía de las formaciones superficiales de origen periglaciar en el valle de Moia (cuenca alta del río Navia-NW ibérico)». En PÉREZ ALBERTI, A.; MARTINI, P.; CHESTWORTH , W. \& MARTINEZ CORTIZAS, A. (Eds.): Dinamica y evolución de medios cuaternarios. pp. 79-90. Santiago.

VALCÁRCEL DÍAZ, M; BlANCO ChAO, R; MARTÍNEZ CORTIZAS, A. \& PÉREZ ALBERTI, A (1998): «Estimación de las paleotemperaturas en Galicia durante el último ciclo glaciar a partir de datos geomorfologicos y climáticos». En A. GÓMEZ ORTIZ \& F. SALVADOR FRANCH (Eds.): Investigaciones recientes de la Geomorfología española. pp. 767-770. Barcelona.

VAN VLIET-LANÖE, B. (1986): «Le pédocomplexe du dernier interglaciaire (de 125000 à 75000 BP). Variations de facies et signification paléoclimatique du sud de la Pologne á L'ouest de la Bretagne». Bulletin de L'Association française pour l'étude du Quaternaire. 1986- 1,2, P. 139-150. 
VAN VLIET-LANÖE, B. (1989): «Dynamics and extent of the Weichselian permafrost in Western Europe (Substage 5E to Stage 1)».Quaternary Internacional.Vols3/4.P.109-113.

VAN VLIET-LANÖE, B. (1990): «Le pedocomplexe de Warneton: Ou en est-on? Bilan paleopedologique et micromorphologique». Quaternary, 1. P: 65-76.

WALKER, R.G. (1992): Facies, facies models and modern stratigraphie concets. In Walker, R.G. \& James, N.P. (Eds.): Facies models: response to sea-level change. Geological Association of Canada. Toronto, 1-14. 


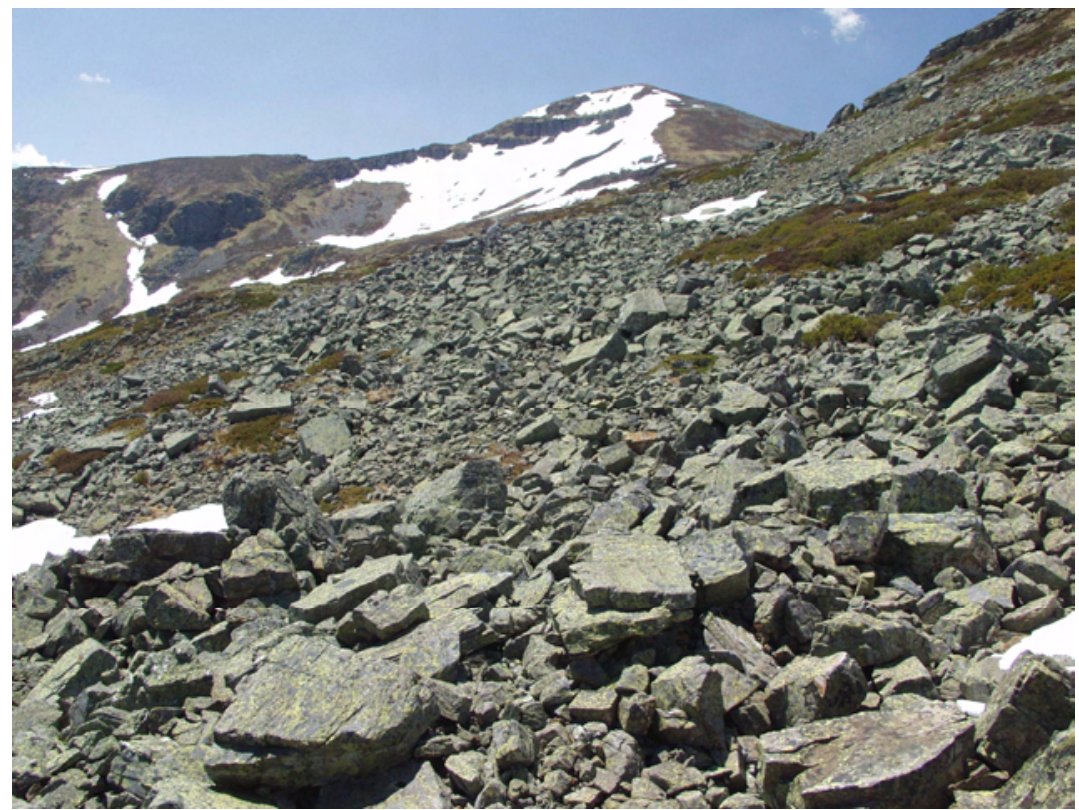

Figura 1. Ladera de bloques. Vertiente oriental de la Sierra de Ancares (León).

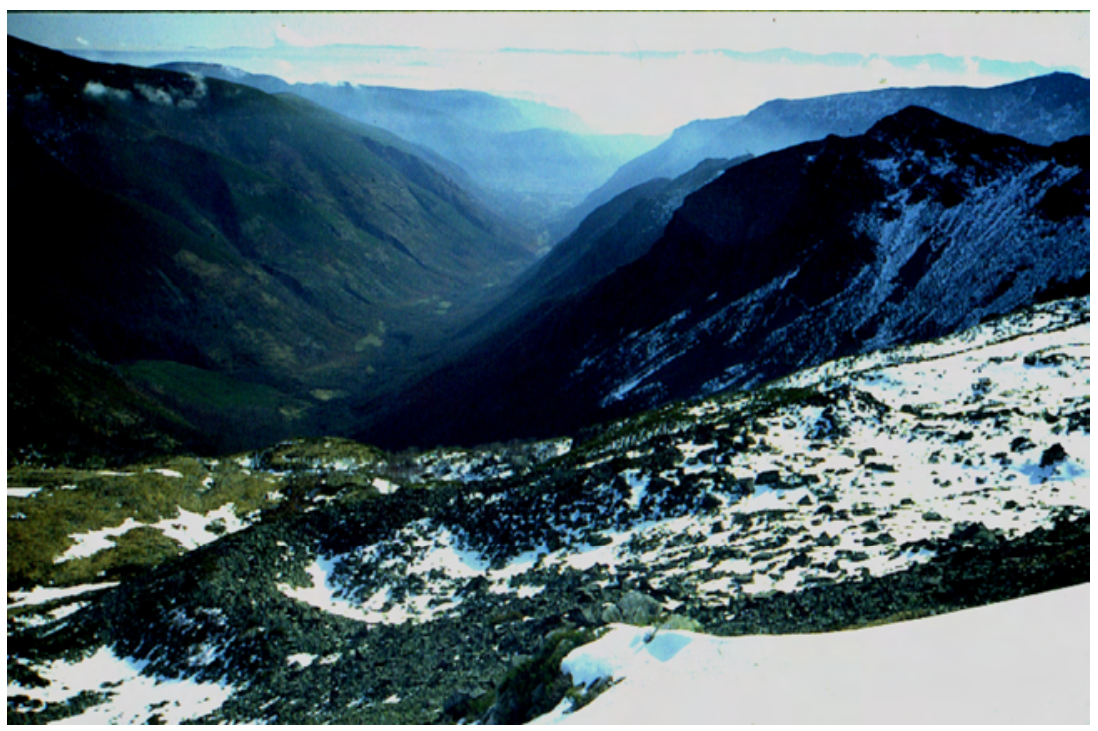

Figura 2. Glaciar rocoso fósil emplazado en la cabecera del valle de Burbia. Sierra de Ancares (León). 


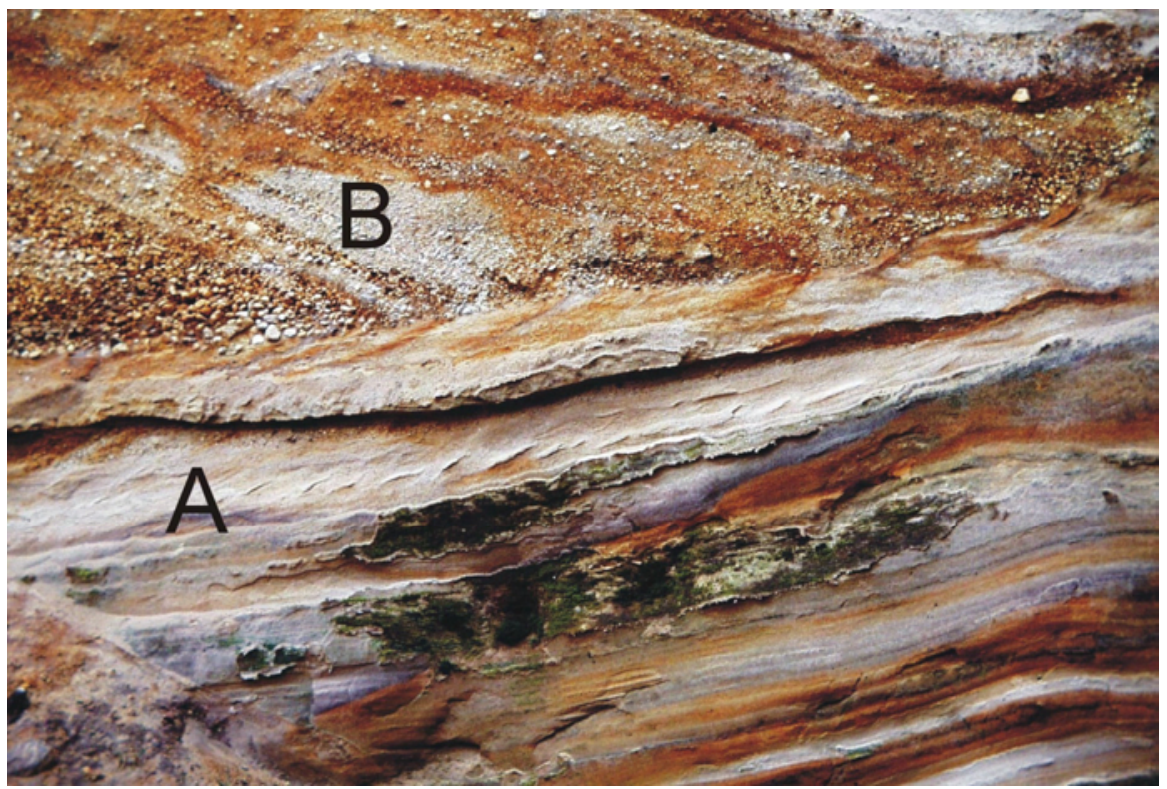

Figura 3. Afloramiento en Pías (Zamora). A: ritmitas; B: delta.

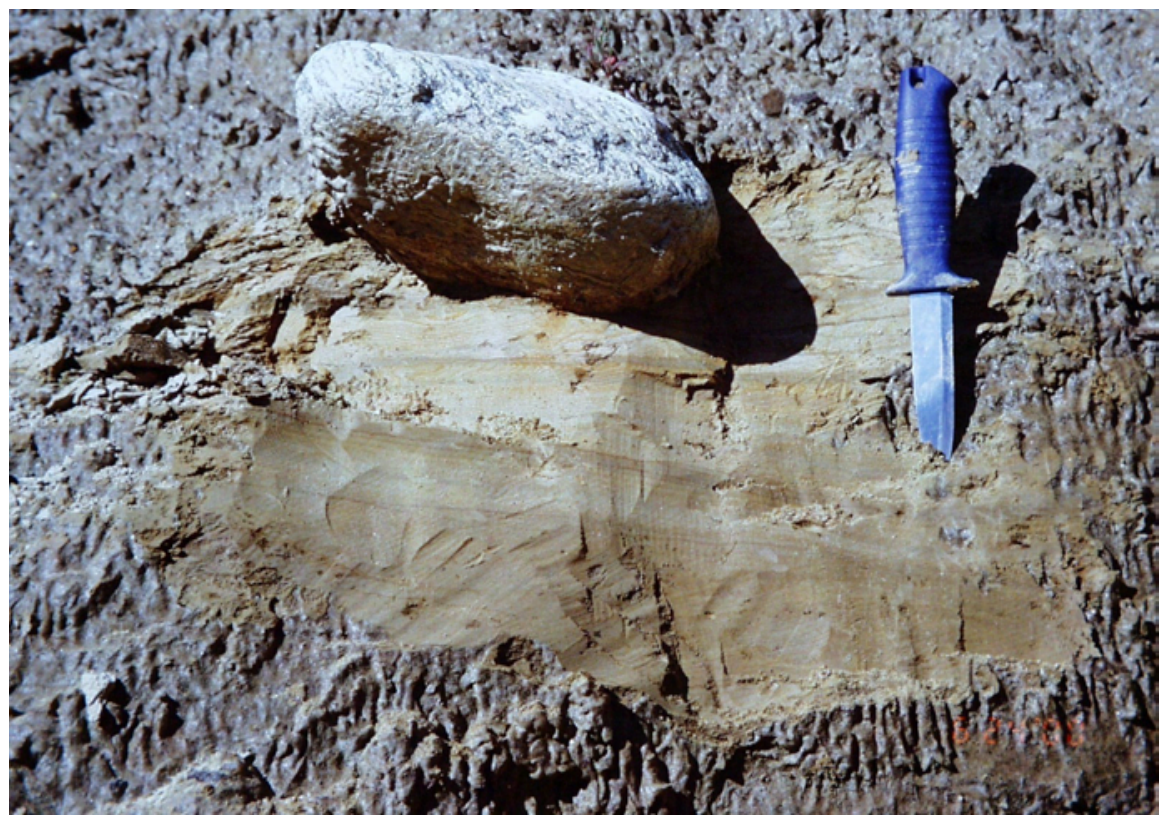

Figura 4. Drpstone incrustado en las ritmitas de Pías (Zamora). 


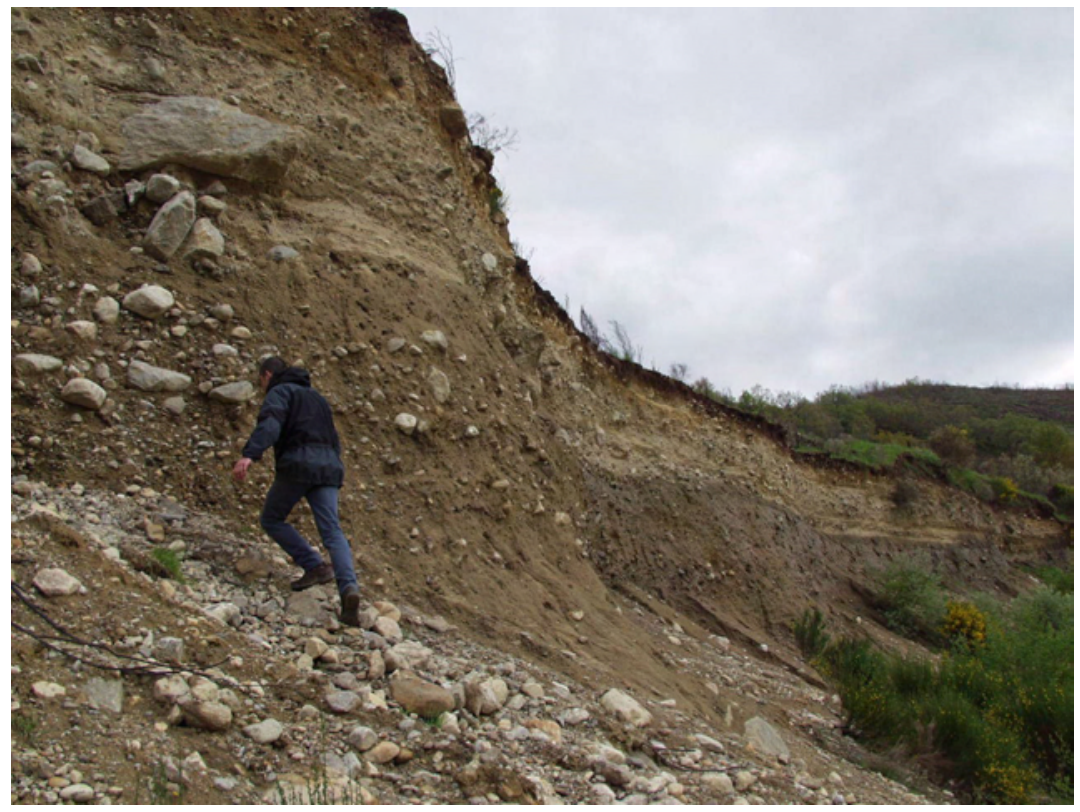

Figura 5. Acumulación de till en Pías (Zamora).

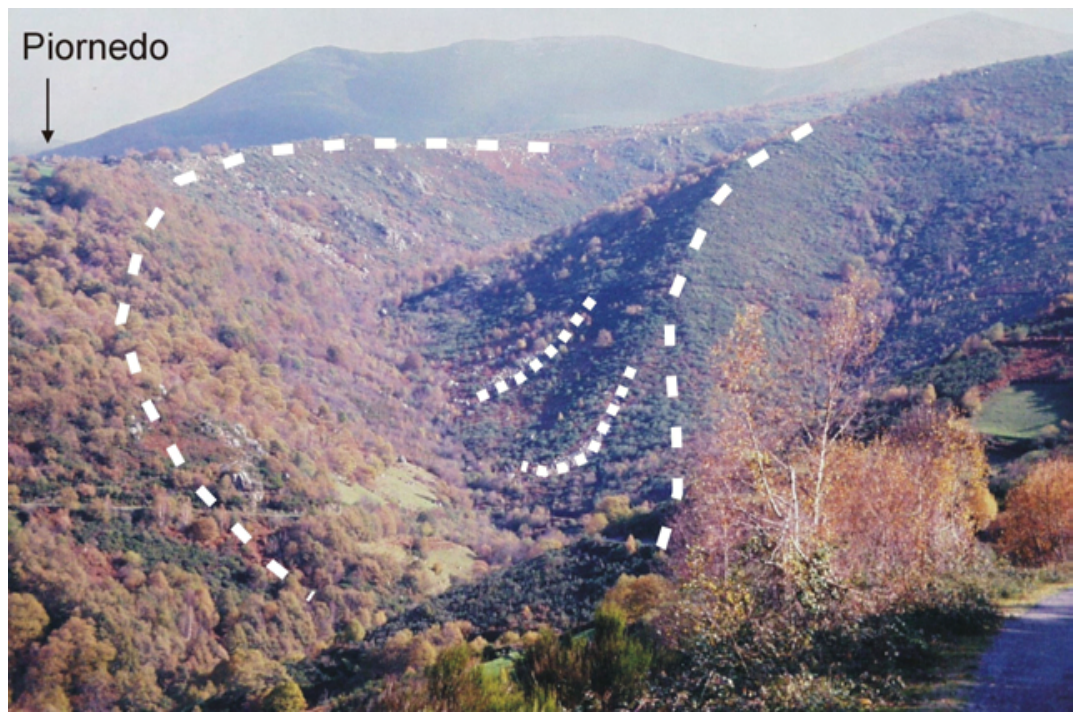

Figura 6. Complejo morrénico fronto-lateral del valle de Piornedo. Sierra de Ancares (Lugo). 


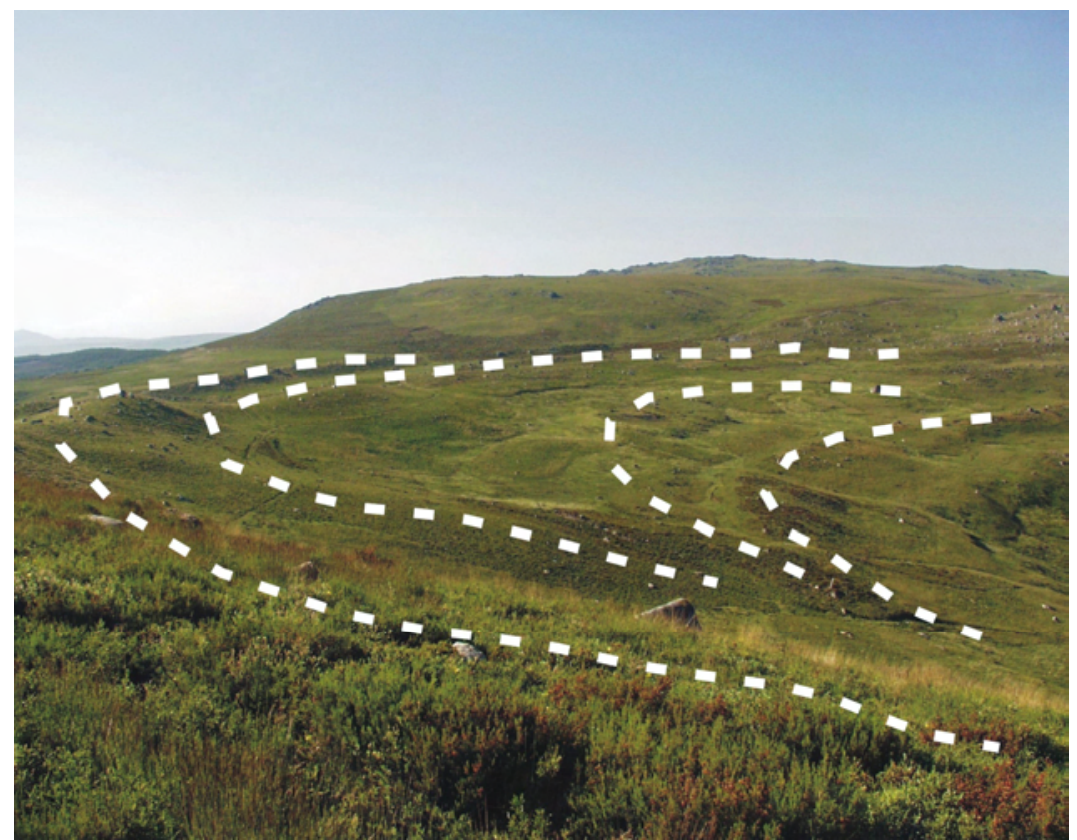

Figura 7. Complejo morrénico fronto-lateral del valle de Bibei (Cepedelo, Ourense).

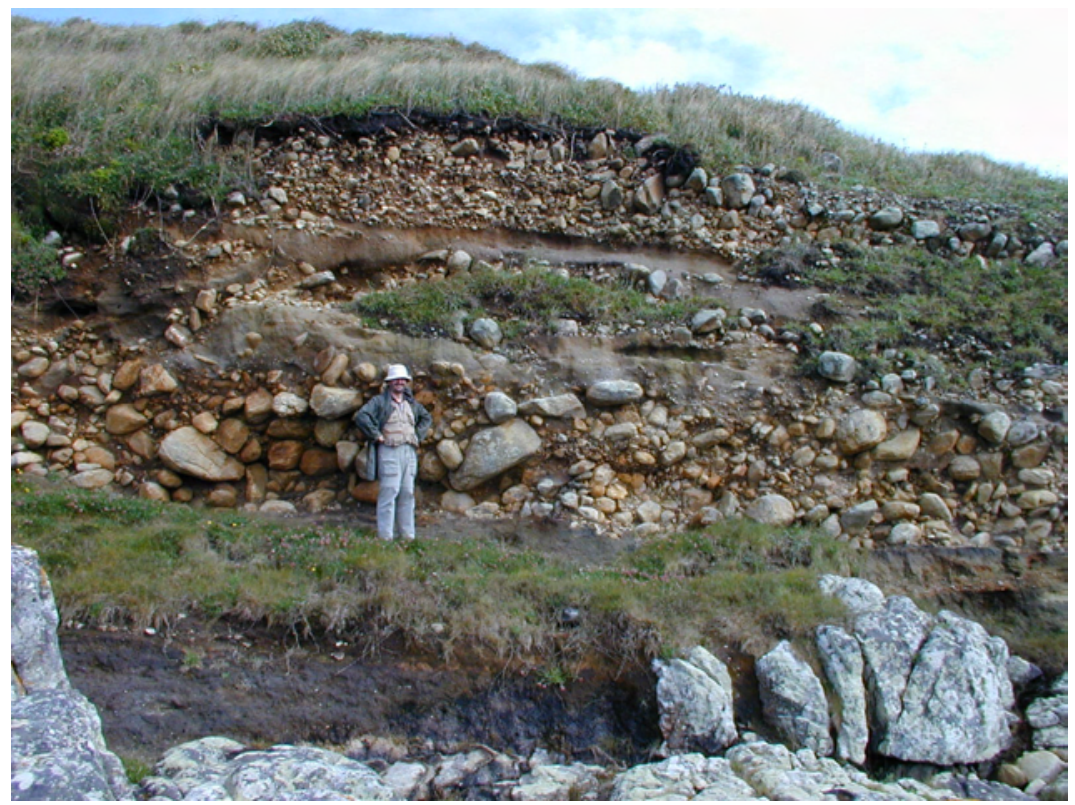

Figura 8. Depósito de origen frío en San Xiao. Pontevedra. 


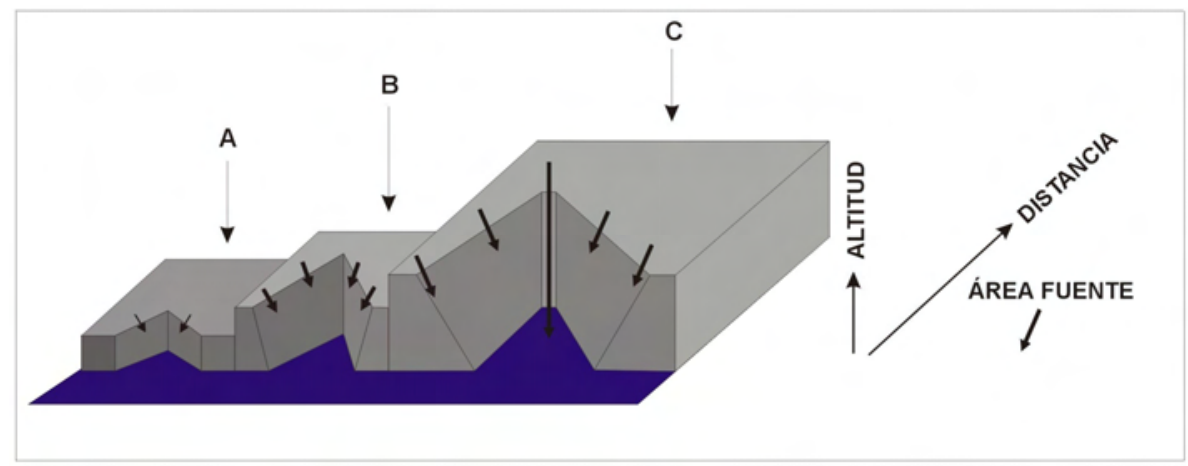

Figura 9. Factores locales que influyen en la caracterización sedimentaria de los depósitos de la costa gallega.

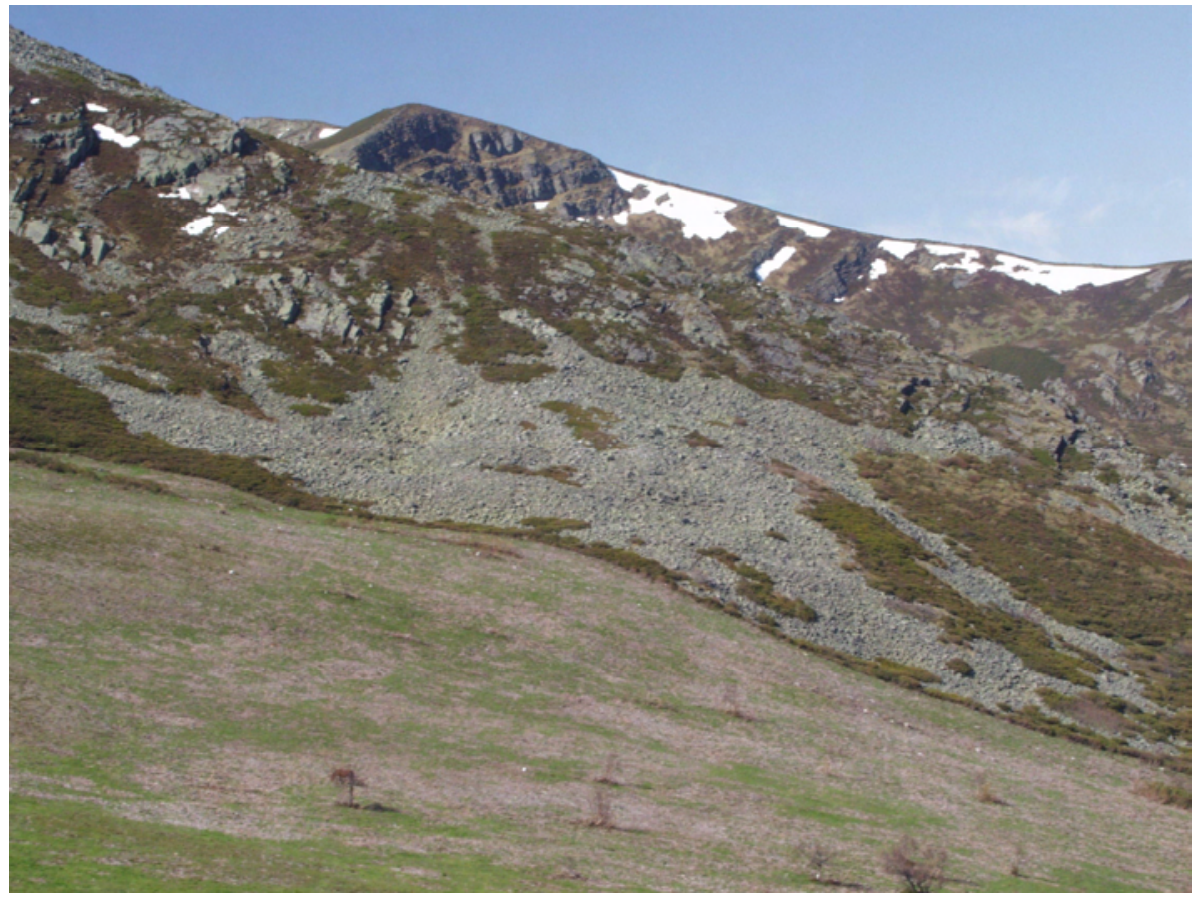

Figura 10. Glaciar rocoso de Peñas Apañadas. Sierra de Ancares (Lugo). 


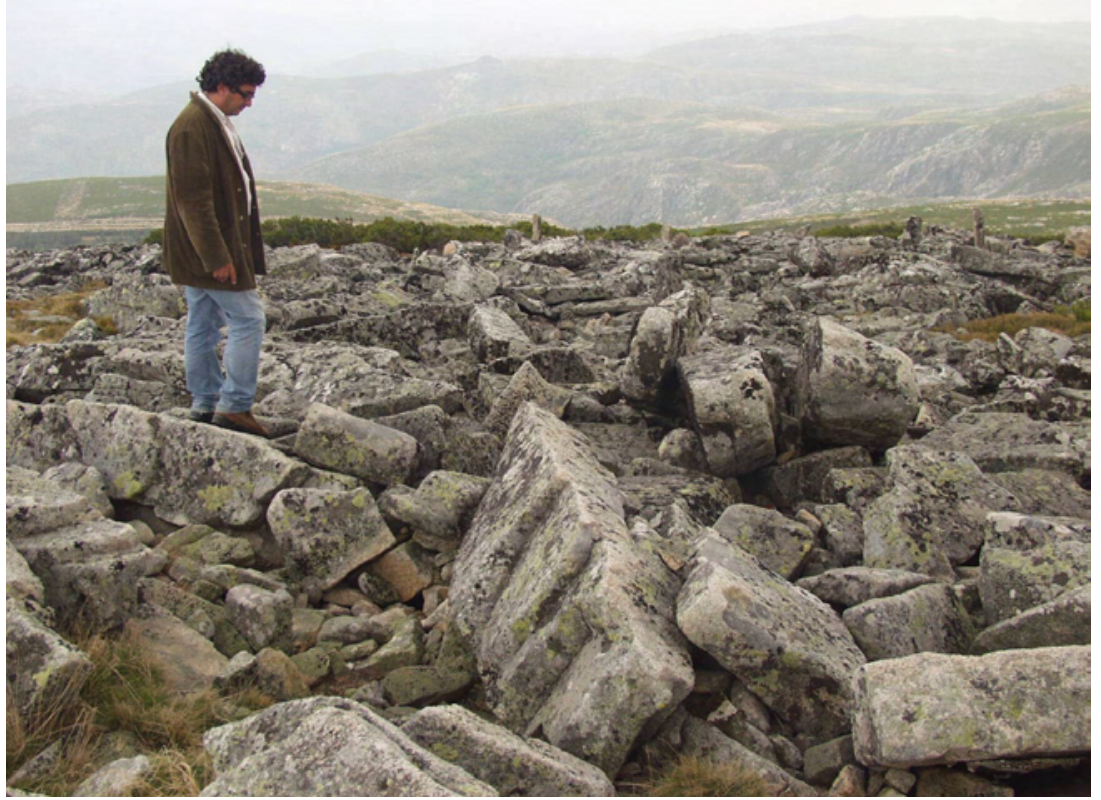

Figura 11. Campo de bloques de cumbre en Manzaneda. Sierra de Queixa (Ourense).

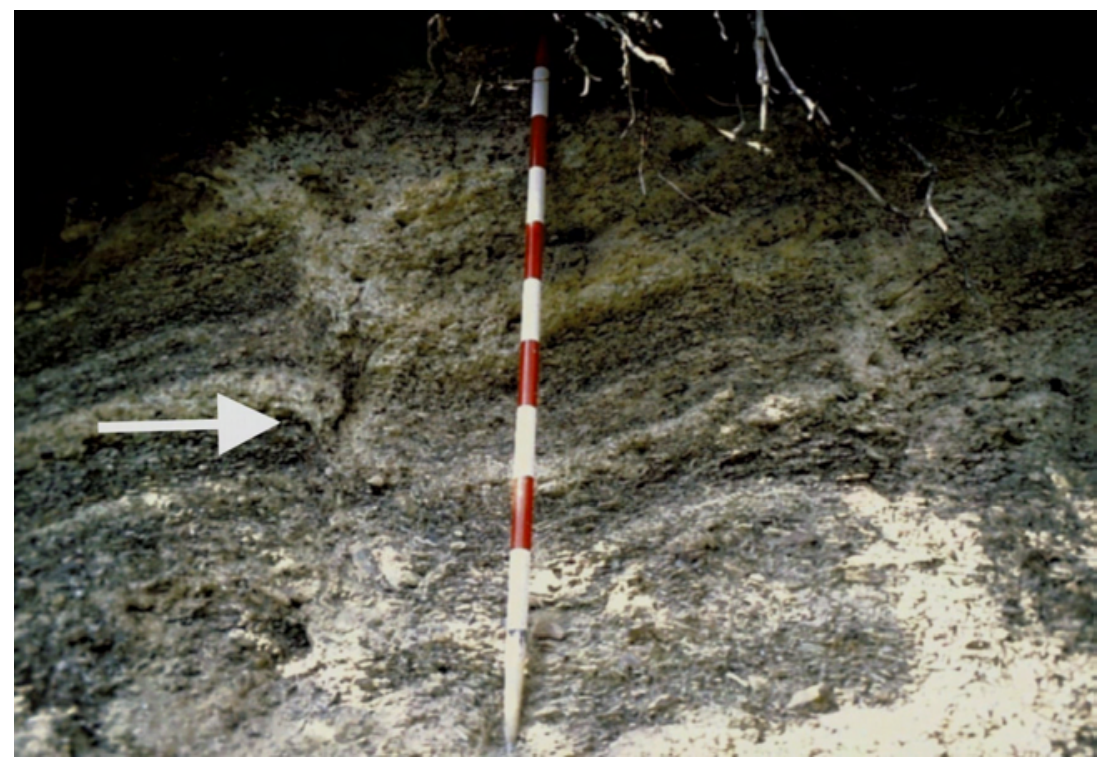

Figura 12. Cuña de hielo fósil en el valle del río Moia. Navia de Suarna. Lugo. 

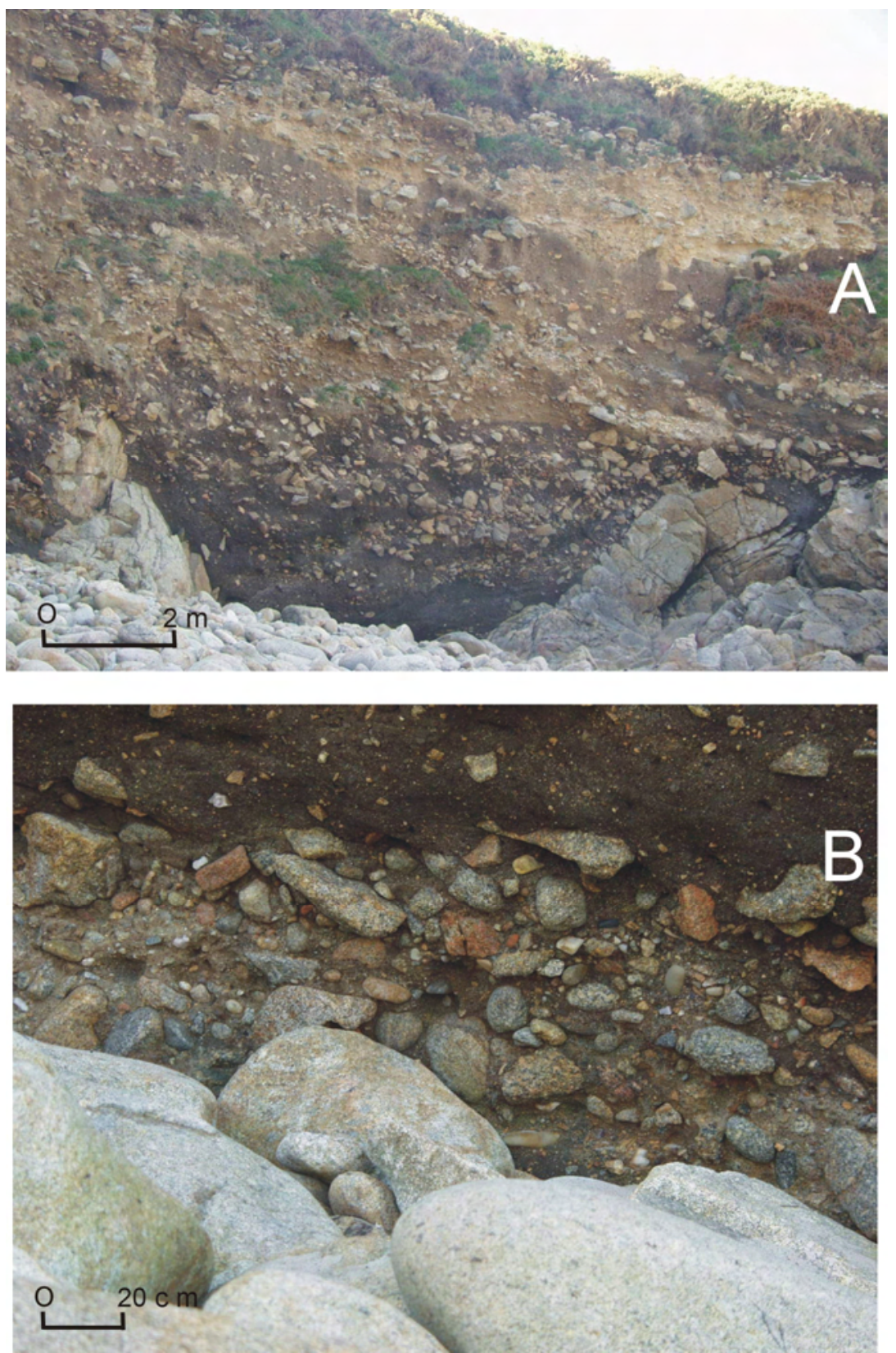

Figura 13. Depósitos costeros en Arnela (Muxía, A Coruña). A: heade; B: playa fósil. 


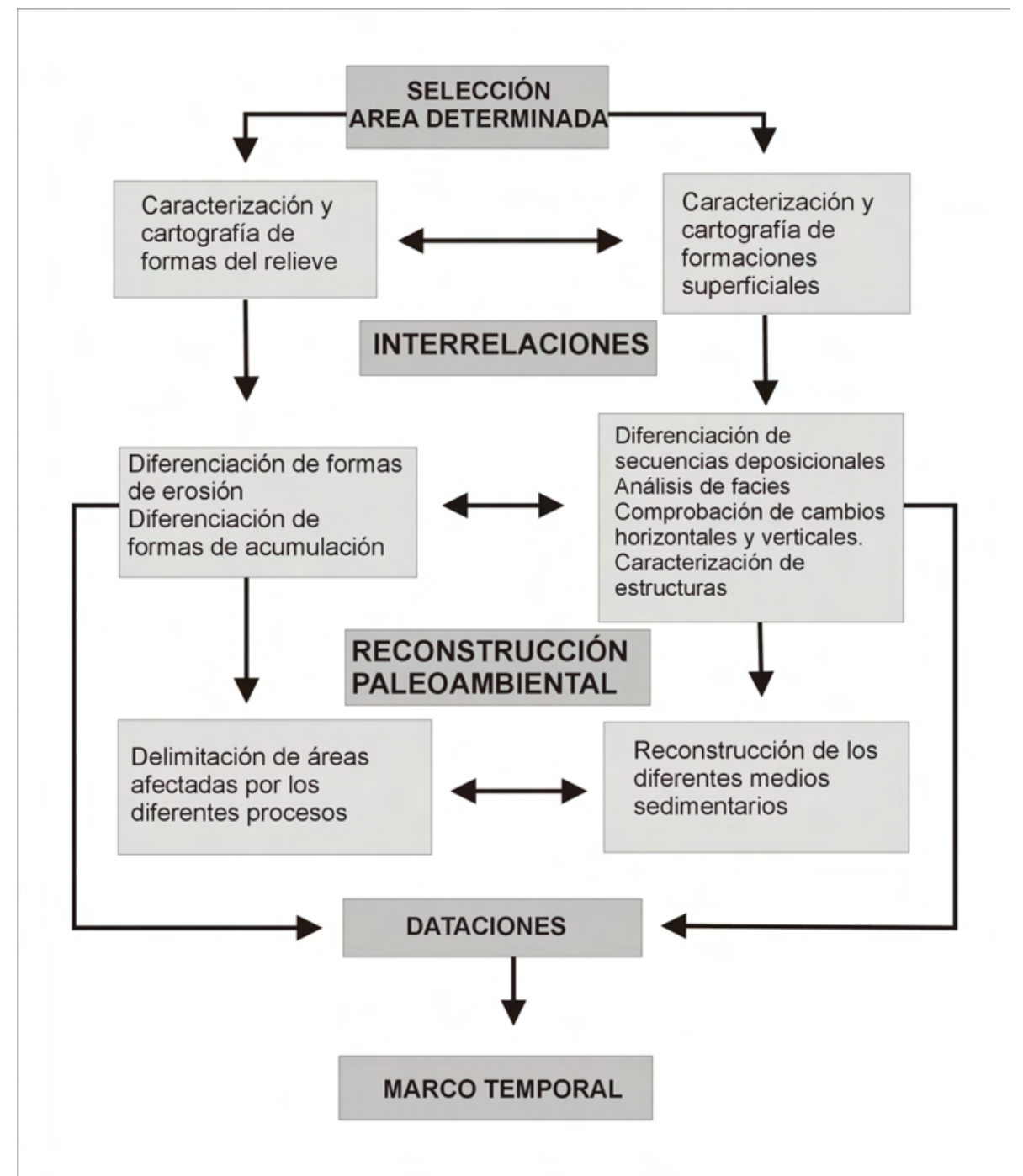

Figura 14. Secuenciación metodológica propuesta en la reconstrucción paleoambiental. 